\title{
Efficiency of Threats in Interpersonal Communication
}

\author{
Gennady Vasilyevich Glukhov ${ }^{1} \&$ Irina Anatolyevna Martynova ${ }^{1}$ \\ ${ }^{1}$ Department of Foreign Languages, Samara State University of Economics, Samara, Russian Federation \\ Correspondence: Irina A. Martynova, Department of Foreign Languages, Samara State University of Economics, \\ building 141, Sovetskoy Armii St., 443090, Samara, Russian Federation.
}

\author{
Received: March 11, 2015 Accepted: March 30, 2015 Online Published: May 22, 2015 \\ doi:10.5539/res.v7n9p60 URL: http://dx.doi.org/10.5539/res.v7n9p60
}

\begin{abstract}
It is common knowledge that threats are typically motivated by a desire to strike fear in others. Fear appeals have received much attention in various disciplines over the last six decades and these studies have collectively garnered comprehensive results. Still, several inadequacies remain. One of neglected areas in the field of threatening communication is the lack of research on fear appeal themes in interpersonal communication. Few researchers have addressed the problem of analyzing the content of fear appeal. The paper broadens current knowledge of "threat content - threat response" correlation. To this end, firstly, threats are analyzed from a theoretical perspective to reveal their dimensions and function in communication. Then contents of threatening interactions are analyzed and statistically examined in terms of response efficacy. To this purpose, responses to threats are extracted and subsequently classified in order to find out whether addressees' responses indicate any tendency about the outcome of an interaction. The implications drawn from this study allow us to consider how appeal to certain types of fear influences the efficiency of threatening messages.
\end{abstract}

Keywords: verbal threats, fear appeal, interpersonal communication, threat responses, threat efficiency

\section{Introduction}

Threats, as a specific type of verbal aggression, occur in many areas of human involvement in the society at large. They are considered to be motivated by "a desire to strike fear in others" (Sachs, 2013). Although, according to some scholars, threats are not among the most efficient strategies for gaining compliance (Kellerman, 1996), they are still quite frequently employed instances of verbal aggression recorded by researchers of communication (for details, see Deans, 2001).

Apart from Gale (2010) there is a general lack of comprehensive studies on threats. Much of the past research has explored different aspects of threats (e.g., Salgueiro, 2010; Haigh, 2011; Muschalik, 2014), but comparatively few studies have addressed specifically the problem of correlation between content of threats and their effectiveness in the field of interpersonal communication. Researchers have not treated that problem in much detail, and it was difficult to discriminate whether certain kinds of threats resulted in better or worse outcomes. Thus, understanding the role of threats in interpersonal communication requires comparing their content with their effects. It is through a broader understanding of this correlation that we can continue to enrich our knowledge of the theoretical construct of threatening communication.

Accordingly, the goals of this paper are twofold. First, we aim to investigate the factor of fear appeal that relates to the content of threats. Second, we make the comparison of threat content to successful outcomes to understand the impact of such a factor on the effectiveness of the threat. Thus, the key research question of this study is whether or not there is a correlation between successfully gaining addressees' compliance and a type of fear appeal that a threat embraces.

In this paper, the terms "speaker", "perpetrator" and "aggressor" are used interchangeably to mean a person who delivers a threatening message. By "addressee", "hearer", "target", and "victim", we specifically mean a person at whom this message is aimed and who receives it.

Data for this study were collected using a sample of 525 threats and responses to them extracted from a corpus of 150 modern fictional texts. A combination of quantitative and qualitative approaches was used in the data analysis to answer the research question on 'threat content - threat efficiency' correlation. Thus, the study offers some important insights into the field of threatening communication and sheds some light on how the way a threat is stated may dramatically influence its effect on the target. 
This paper first gives a brief overview of the theoretical dimensions, and summarizes relevant research on threats and their efficiency. The next section is concerned with the data set and the methodology used for this study. The third section presents the findings of the research, focusing on the definite set of fear appeals and highlighting more efficient threatening content. Then, the conclusion gives a brief summary and critique of the findings. Finally, areas for further research are identified.

\section{Literature Review}

Research on threatening communications has primarily come from works based in sociology (Tedeschi, 1983), psychology (Haigh et al., 2011), compliance gaining theory (Kellermann, 1996), Speech Act Theory (Salgueiro,2010), negotiation studies (Shapiro \& Bies, 1994; Galinsky, 2004), forensic linguistics (Fraser 1998, Muschalik, 2014; Gale, 2010), workplace violence (Deans, 2001), and political linguistics (Bratton, 2005; Sechser, 2010). What is covered here is an overview of how different scholars view threatening language. We summarized only those findings which concern more or less all threatening communications, by which psychologists mean "a message conveying one or both of the following elements: the degree of severity and the degree to which one is susceptible to the threat" (Peters et al., 2013). In psychology, a threat per se is defined as a danger of harm or an external stimulus that exists whether or not it is perceived by an individual (Witte, 1992).

Sociologists noted that "threats (as a type of violent behavior) occur in every society" and claim that threats as a social phenomenon "can be understood only in social context" (cited in Deans, 2001, p. 13). Threats, thus, are seen in this paper as linguistic acts including at least two parties - the perpetrator and the target. Perpetrators violate social norms; they maintain power over the victim thus maintaining status, self-image and authority.

Threats are coercive by nature and are used to intentionally influence the behavior of targets by making them choose to comply rather than directly forcing them to comply (for details see Bratton, 2005). Having analyzed the reasons for threatening, psychologists separated: venting anger, instilling fear, attempting to cause a desired result, challenging authority, attracting attention, saving face, or providing humor (Milburn \& Watman, 1981; Fraser, 1998).

Within the framework of Speech Act Theory threats are classified as commissives. That means that they involve a commitment by the speaker to "undertake the course of action represented in the propositional content" (Searle, 1998, p. 149). According to Walton (2014) there are four speech act conditions that have to be met while threatening:

\section{- Preparatory Condition 1}

The hearer has to have reasons to believe that the speaker can bring about the negative consequences in question.

- Preparatory Condition 2

It is presumed by both the speaker and hearer that the negative consequences will not occur without the intervention of the speaker.

\section{- Sincerity Condition}

The negative consequences will not be in the hearer's interests and the hearer would want to avoid them if possible.

\section{- Essential Condition}

The speaker is making a commitment to make the bad consequences occur unless the hearer carries out the action recommended by the speaker (Walton, 2014 p. 113).

Some scholars examined distinctions among different forms of threats. Although, the lack of consistently agreed operational definitions has complicated the thorough examination of the ways threats are made in, it is still possible to provide a general overview. In a comprehensive research by Gale (2010) three distinct categories of threats are defined (examples are ours):

- Direct threat: the action, time, place, and/or victim are clearly stated — not all elements need to be present for it to be direct, but at least two or more need to be present

I'm going to blow you away. I'm going home and I'm going to bring back a grenade.

- Conditional threat: the threat is dependent on the recipient performing some action

If you ever get credit for my work again, that will be the last time you take credit for anybody's work.

- Veiled threat: the action, time, place, and/or victim are not clearly stated and there is no condition the recipient needs to fulfill to stop the threatened action 
You are in big trouble or I'll teach you a lesson (Gale, 2010, p. 272).

However, other authors provide terms which are very similar if not the same to the abovementioned. (Please refer to table 1 - which is intended not as a comprehensive list but as a visual aid.)

Table 1. Difference in terms on types of threats in academic prose

\begin{tabular}{ll}
\hline Threats (in Gale's list) & Counterparts of the terms by other authors \\
\hline Veiled & implied (Meloy et al., 2008) \\
Conditional & contingent (Geiwitz, 1967) \\
& incentive (Scanlon, 2008) \\
& manipulative (in Beller et al., 2005) \\
Direct & noncontingent (Geiwitz, 1967) \\
& nonincentive (Scanlon, 2008) \\
\hline
\end{tabular}

Sachs discussed two more types of threats: compellent and deterrent threats which, in fact, are two sides of the same coin, viz. coercion: compellent threats, made to cause an opponent to stop a current action or to undertake another; deterrent threats, made to cause an opponent to not take a certain action (Sachs, 2013).

So, summing up the academic's and practitioner's views on the nature of threats and following the definition suggested by Gale, the term "threat" will be used here to refer to communicated (written or spoken) speech acts, that are "proffered for the benefit of the speaker and to the detriment of the hearer, that are in the control of the speaker, and that are intended to and have the effect of instilling fear in or intimidating a recipient". (Gale, 2010, p. 14)

To answer the research question we consider one more dimension of threatening communication, i.e. its efficiency. Throughout this paper we refer to the term "efficiency of a threat" in its broadest sense as to the ratio of successful responses performed by addressees to negative ones. To make a threat effective speakers have to make it recognizable by their targets and thereto use reliable strategies and conventional forms of exploiting common ground, shared knowledge and linguistic as well as extra-linguistic context. A series of factors that influence the effectiveness of threats were defined in the social psychological literature. Those factors are discriminated between: factors relating to the speaker (e.g., prior reputation to carry out commitments, the magnitude of likely punishment, social status, out group membership, accommodative behavior or likeability) and factors relating to the target (e.g., the capacity to retaliate, social status, or self-image and self-esteem) (for an overview, see Sinaceur \& Neale, 2005). It is often noted in academic works that although coercive threats are more effective on average when they come from disproportionally powerful perpetrator, they still can backfire in unintended ways, e.g., provoke counter threats (Galinsky \& Liljenquist, 2004; Goldenberg \& Arndt, 2008; Peters et al., 2013). Despite unpredictability of threat responses, threats are extensively employed strategy of inducing fear to make a victim comply. However, there is still considerable uncertainty with regard to how the content of a threat correlates with its efficiency and assists the speaker in the process of compliance gaining. Thus, the characteristics of threats cannot be fully understood without examining of how the very nature of the threat may affect its efficiency.

\section{Data and Methodology}

For this study, we have looked at a corpus of 150 modern fictional texts published from 1990 until 2014. This gave us a corpus of 525 threats employed by speakers in the process of interpersonal communication. This is a small corpus compared to many published ones, but for a project of this size it would seem to be large enough. There can be no doubt that corpora of naturally occurring data are the best way to study threats and their efficiency, but one of the problems that analysts often encounter in gathering naturally occurring speech data is that the data required for studies of threatening communication are oftentimes highly sensitive in nature and often impossible to obtain.

With these considerations in mind, there are still definite benefits in utilizing a data set taken from modern fiction. First, the data are accompanied by a vast context and it would be difficult to see how meaningful research of threats can be provided outside of their context, since "context is - inherently and ultimately unpredictable" (Storey, 1995, p. 74). Moreover, the choices of fictional characters are better explained. 
The methodological tools that this paper utilizes are largely those from content analysis and semantic research. So, we do not limit ourselves to a single methodological approach, but aim to use both methods to gain a better understanding of the content-efficiency correlation of threatening utterances.

Content analysis was used with a twofold purpose. Firstly, we examined all the threat-related words (e.g., violent physical action verbs) generated by speakers in the threatening interactions. We analyzed the linguistic data semantically in terms of with what the speakers threaten and what punitive measures the speakers are going to imply. Secondly, we utilized content analysis to get a clear idea of response category. That is, we tried to find out if targets tend to compliance or rejection of speakers' threats. As has been mentioned threats appeal to fear, that is why fear-related words (e.g., marking verbal responses, describing emotional states and paralinguistic mechanisms to express emotion) were examined in the context of reactive speech acts.

Then we gathered precise numerical data to examine in what ways content of threatening utterances influence their efficiency, i.e. threats were analyzed statistically to reveal both the most frequently utilized contents and the most repeatedly met cases of compliance. Results are presented in the next section of this paper.

\section{Results}

This section presents illustrative findings from our research. The first factor we investigate is fear appeal contained in threats. In this article we do not deal with the form of "fear appeal" used in fear appeal theory and understood as "a persuasive message designed to scare people by describing the terrible things that will happen to them if they do not do what the message recommends" (Witte, 1992, p. 329). Rather, we deal with the term "fear appeal" in its broadest sense to refer to all attempts of speakers to address victims' emotion of fear. Through the arousal of fear associated with a threat perpetrators try to make addressees get such states of mind that run counter to the reason and logic that ought to guide the rational human being thus motivating hearers to comply with recommended course of action. To better understand the type of fear perpetrators appeal to, we semantically analyzed the verbs of sanctions. Verbs, presented in threats, can be grouped according to the direction of their destructive strategy. Firstly, they mark speakers' intention to purposefully inflict pain or physically confine their targets, i.e. they could broadly represent threats to victims' corporal integrity, e.g.:

(1) How'd you like a bust in the nose? (Wolff, 2003, P. 84)

(2) I'm going to kill you. (Love, 2002, p. 54)

Secondly, speakers threaten with public revelation or denunciation, or sometimes with deprivation of something that is very important (e.g., economically or psychologically) to their targets. It is supposed that such sanctions would result in social exclusion or psychological suffering of victims. These threats can be broadly separated as threats to social identity, e.g.:

(1) "You're gonna burn this meat, girl. And if you do, you're out of the crew". Being yelled at was the last straw. Jennifer began to sob uncontrollably, but she continued to cook. (Goldsmith, 2002, p. 225)

(2) "There, you see?" the man on crutches snapped. "Now, you can either grant his dying wish and let us sprinkle his ashes in the sanctuary, or I tell Father Knowles how we've been treated." The altar boy hesitated, ... Then the altar boy stepped aside to let the three people pass. (Brown, 2005: 352) or "If you don't control your charging, I'll cut up the charge cards." There was another silence. Then tears. Tears and a ravenous hunger for revenge. (Wolff, 2005, p. 17)

And, finally, the last type of threats was defined. Verbs in them do not specify any particular sanction. To introduce clarity here aggressors have to employ non-verbal and paralinguistic mechanisms, including facial expressions, gestures, posture, tone of voice, and the like, e.g.:

(1) I've really been watching you.

(2) No locks on the doors, though, are there?

This category is similar to the definition of veiled threats used in Gale's classification (Gale, 2010).

So, we grouped all threats in three broad types, but since the results on nonspecified general threats could not shed any light on the research questions stated in this paper they were excluded from our further examination.

Turning now to the quantitative analysis of our sample, we examined contents of threats according to perpetrators' preferences. Figure 1 shows the percentage of threats appealing to two different types of addressees' fear. 


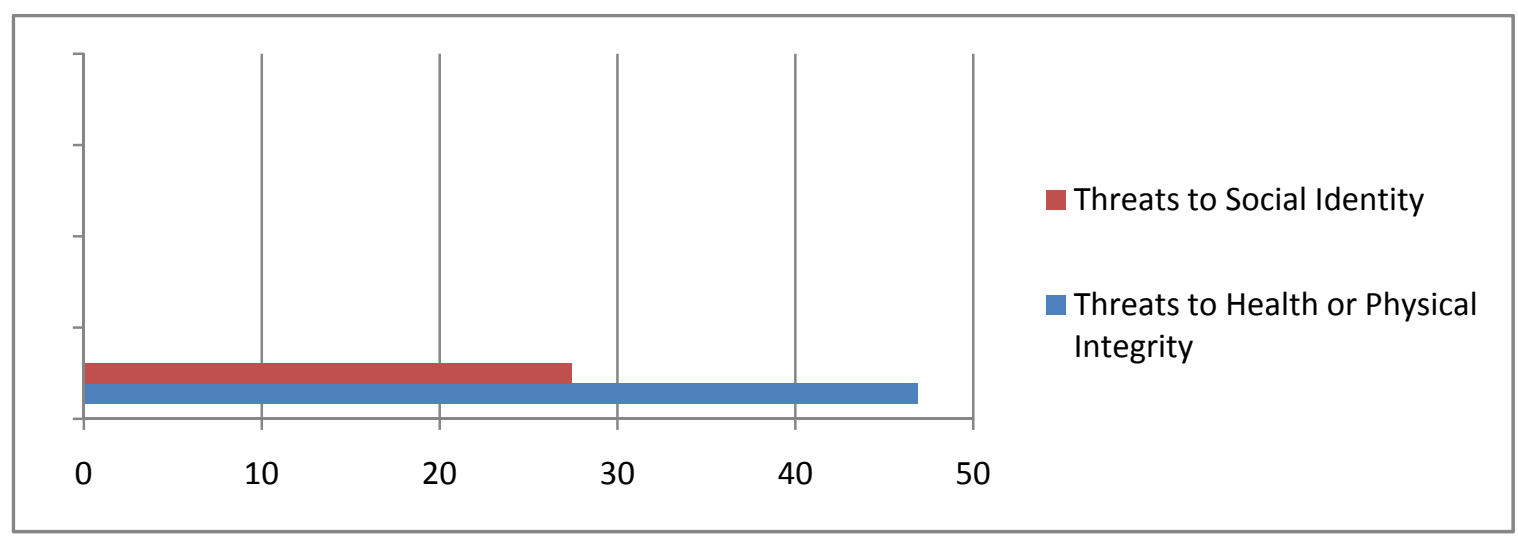

Figure 1. Distribution of fear appeals in content of threatening utterances

It can be seen from the data in Figure 1 that the group of threatening strategies in which speakers utilize victims' fear of being physically hurt or damaged is significantly bigger than the group representing appeal to targets' fear of being exposed to social ostracism or exclusion ( $46.9 \%$ and $27.4 \%$ respectively).

With this in mind we turned to the evidence on interdependence between content and efficiency of threats. The results of this analysis are demonstrated in Figure 2. The aim of this phase was to test correlation between the type of fear appeal and success of threatening message.

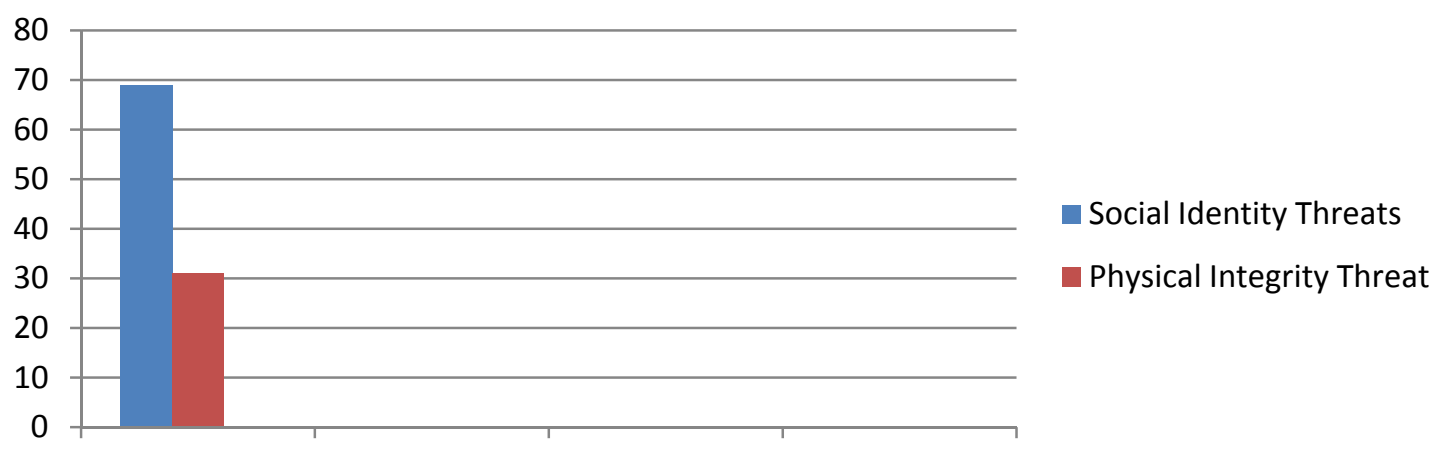

Figure 2. Efficiency—Content correlation

As the findings of the analysis show in $69 \%$ of cases speakers gained compliance having threatened to social identity of addressees. With threats to physical integrity menacing speech acts were successful only in $31 \%$ of cases, thus demonstrating low effectiveness of such threats.

\section{Discussion}

Comparing the two results, it can be seen that whereas perpetrators tend to appeal to fear of being hurt victims demonstrate a very definite trend to comply in cases of being socially threatened. It is apparent from this evidence that fear of physical violence yields to other fears. Consequently, appeals to the fear of social ostracism or social exclusion are more efficient in modern society than appeals to primitive fears of physical violence. This concurs well with Izard (1991), who stated that more often than being afraid of physical pain we are scared of our pride being wounded and our self-esteem lowered. This finding also corroborates the ideas of Solomon et al. who suggested that fear of social exclusion is an effective attitude changer (Solomon et al., 2010).

It is also interesting to note an unanticipated implication that has emerged from the data comparison. 


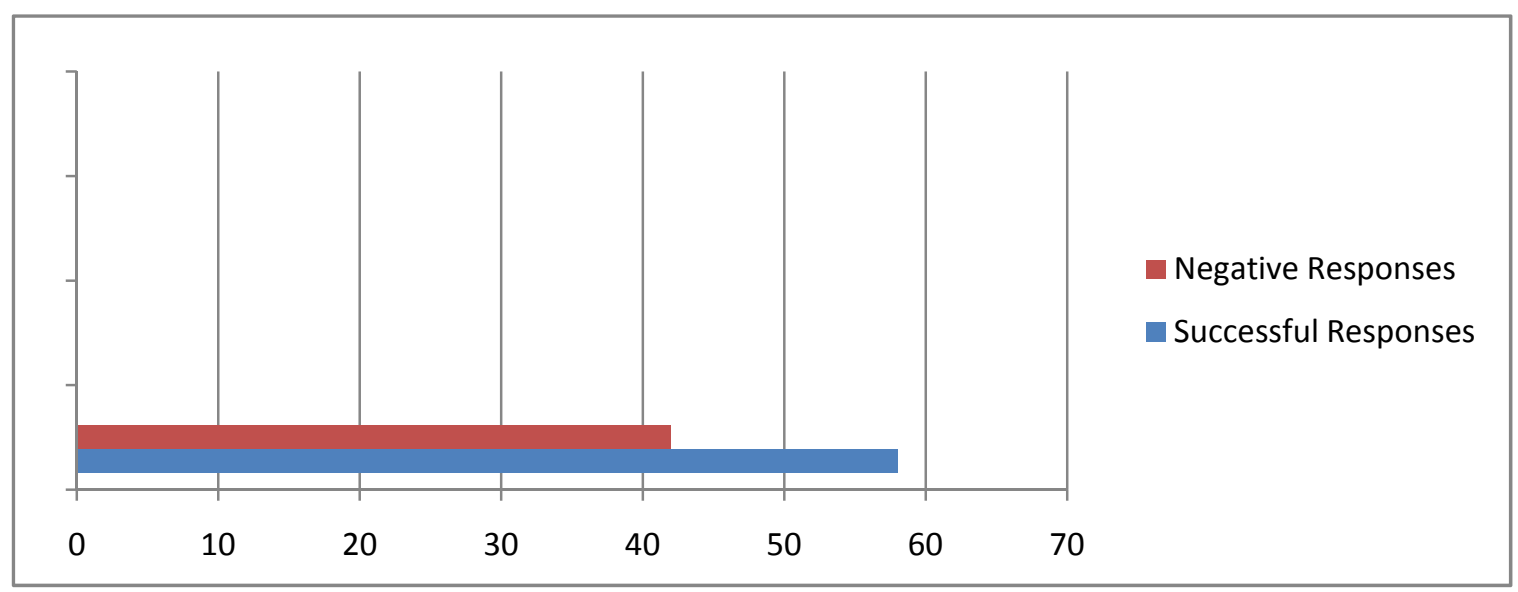

Figure 3. Percentage of successful and negative responses to threats in the sample

Comparing the ratios of successful and negative responses, it can be seen that in $58 \%$ of cases addressees demonstrated compliance while in $42 \%$ of cases perpetrators failed in their attempt to get obedience. This result indicates that it is difficult and oftentimes impossible to forecast the response to threats due to the whole set of prerequisites to be taken into consideration. This is in line with the evidence from fear appeal theory, which suggests that information about the severity of possible negative consequences may prompt defensive responses (Peters et al., 2013). Another possible explanation for this might be found in psychological studies of fear. Many scholars hold the view that being instinctive by nature, fear cannot be controlled. Consequently, addressees' ability to process information comes to nothing oftentimes resulting in reactive aggression, $\mathrm{cf}$.

I got in a fight one time with a really big guy, and he said, "I'm going to mop the floor with your face." I said, "You'll be sorry." (Haig, 2005, p. 53)

Although it has been reported (Baron \& Richardson, 1994) that reactive response to fear may as well result in constructive behavior when victims, mobilizing their resistance to fear, are able to exercise control over their emotions. Curbed with intellect, fear intensifies perception and rational problem-solving ability. A person can exceed his limits, cf.

"We're taking Mr. Teabing for a drive," Rémy said, still backing up. "If you call the police, he will die. If you do anything to interfere, he will die. Is that clear?" "Take me," Langdon demanded, his voice cracking with emotion. "Let Leigh go."(Brown, 2005)

\section{Conclusions}

In general terms, the current findings suggest that content and efficiency of threats interact in important ways. Threats appealing to "social" fears elicited more concessions by targets than threats aimed at "physical" fears. Specifically, addressing fears of social exclusion or psychological suffering affects targets' response more effectively.

The current results also provide evidence for the idea of high indeterminism of threat responses. That means that not all threat responses could be wholly predicted even with all prerequisites taking into account.

Our analyses revealed a surprising discrepancy in perpetrators' preferences and efficiency of threats. From all the possible set of fear appeals speakers seem to opt for those ones that elicit fear less effectively. Thus, contrary to our expectations, the most effective threats are the least employed in the process of interpersonal communication. As the results of this study do not explain the occurrence of this contradiction more research on the topic needs to be taken before this lack of correspondence is more clearly understood.

In addition, the authors of the current study acknowledge a number of limitations of the study, including the fact that the database is limited primarily to fictional texts. So, these results therefore need to be interpreted with caution and cannot be extrapolated to all fields of communication studies.

\section{References}

Baron, R. A., \& Richardson, D. R. (1994). Human Aggression. N. Y.: Plenum Publishing Co. 
Beller, S., Bender, A., \& Kuhnm, G. (2005). Understanding conditional promises and threats. Thinking and Reasoning, 11(3), 209-238. http://dx.doi.org/10.1080/13546780442000141

Bratton, P. (2005). When is coercion successful? Naval War College Review, 58(3), 99-120.

Deans, C. (2001). Nurses' responses to work-related aggression (Unpublished doctoral dissertation). Victoria University of Technology, Melbourne, Australia.

Fraser, B. (1998). Threatening revisited. Forensic Linguistics, 5(2), 159-173. http://dx.doi.org/10.1558/sll.1998.5.2.159

Gale, T. A. (2010). Ideologies of Violence: A Corpus and Discourse Analytic Approach to Stance in Threatening Communications (Unpublished doctoral dissertation).University of California, Davis, USA.

Galinsky, A. D., \& Liljenquist, K. A. (2004). Putting On the Pressure: How to Make Threats in Negotiation. Harvard Business Publishing Newsletters.

Geiwitz, P. J. (1967). The Effects of Threats on Prisoner's Dilemma. Behavioral Science, 12, 232-233. http://dx.doi.org/10.1002/bs.3830120307

Goldenberg, J. L., \& Arndt, J. (2008). The implications of death for health: A terror management health model for behavioral health promotion. Psychological Review, 115(4), 1032-1053. http://dx.doi.org/10.1037/a0013326

Greenawalt, K. (1989). Speech, Crime, and the Uses of Language. New York: Oxford University Press.

Haigh, M., Stewart, A. J., Wood, J. S., \& Connell, L. (2011). Conditional advice and inducements: Are readers sensitive to implicit speech acts during comprehension? Acta Psychologica, 136(3), 419-424. http://dx.doi.org/10.1016/j.actpsy.2011.01.009

Izard, C. E. (1991). The Psychology of Emotions. New York: Springer. http://dx.doi.org/10.1007/978-1-4899-0615-1

Johnston, A. C. (2010). Fear appeals and information security behaviors: An empirical study. MIS Quarterly, 34(3), 549-566.

Kellermann, K., \& Shea, B. (1996). Threats, Suggestions, Hints, and Promises: Gaining Compliance Efficiently and Politely. Communication Quarterly, 44(2), 145-165. http://dx.doi.org/10.1080/01463379609370007

Meloy, J. R., Mohandie, K., \& Green, M. (2008). A forensic investigation of those who stalk celebrities. In J. R. Meloy, L. Sheridan, \& J. Hoffmann (Eds.), Stalking, threatening, and attacking public figures: A psychological and behavioral analysis (pp. 37-54). New York, NY: Oxford University Press.

Milburn, T. W., \& Watman, K. H. (1981). On the nature of threat: A psychological analysis. New York, NY: Praeger Publishers.

Muschalik, J. (2014, May). "Is that a threat?"-The Pragmatics of Threatening and the Interpretation of Statements in Court (Abstract). Retrieved from https://beyondwords2014.files.wordpress.com/2014/04/julia-muschalik-the-pragmatics-of-threatening-and-t he-interpretation-of-statements-in-court.pdf

Peters, G-J. Y., Ruiter, R. A. C., \& Kok, G. (2013). Threatening communication: A critical re-analysis and a revised meta-analytic test of fear appeal theory. Health Psychology Review, 7(1), 8-31. http://dx.doi.org/10.1080/17437199.2012.703527

Sachs, B. (2013). Why Coercion is Wrong When It's Wrong. Australasian Journal of Philosophy, 91(1), 63-82. http://dx.doi.org/10.1080/00048402.2011.646280

Salgueiro, A. B. (2010). Promises, Threats, and the Foundation of Speech Act Theory. Pragmatics, 20(2), 213-228. http://dx.doi.org/10.1075/prag.20.2.05bla

Scanlon, T. M. (2008). Moral Dimensions: Permissibility, Meaning, Blame. Cambridge, MA: Harvard University Press.

Searle, J. R. (1998). Mind, language and society: Philosophy in the real world. New York: Basic books.

Sechser, T. S. (2010). Goliath's Curse: Coercive Threats and Asymmetric Power. International Organization, 64(4), 627-660. http://dx.doi.org/10.1017/S0020818310000214

Sinaceur, M., \& Neale, M. A. (2005). Not All Threats are Created Equal: How Implicitness and Timing Affect the Effectiveness of Threats in Negotiations. Group Decision and Negotiation, 14, 63-85. 
http://dx.doi.org/10.1007/s10726-005-3876-5

Shapiro, D. L., \& Bies, R. J. (1994). Threats, Bluffs, and Disclaimers in Negotiations. Organizational Behavior and Human Decision Processes, 60, 14-35. http://dx.doi.org/10.1006/obhd.1994.1073

Storey, K. (1995). The language of threats. Forensic Linguistics, 2(1), 74-80.

Tedeschi, J. T. (1983). Social influence theory and aggression. In R. G. Green, \& E. I. Donnerstein (Eds.), Aggression: Theoretical and empirical reviews (pp. 68-86). New York: Academic Press.

Walton, D. (2014). Speech Acts and Indirect Threats in Ad Baculum Arguments: A Reply to Budzynska and Witek. Argumentation, 28(3), 317-324. http://dx.doi.org/10.1007/s10503-014-9318-2

Witte, K. (1992). Putting the fear back into fear appeals: The extended parallel process model. Communication Monographs, 59(4). http://dx.doi.org/10.1080/03637759209376276

\section{Copyrights}

Copyright for this article is retained by the author(s), with first publication rights granted to the journal.

This is an open-access article distributed under the terms and conditions of the Creative Commons Attribution license (http://creativecommons.org/licenses/by/3.0/). 